\title{
ANÁLISE SOBRE A DISPOSIÇÃO PARA IMPLEMENTAÇÃO DA LOGÍSTICA REVERSA NO VAREJO SUPERMERCADISTA
}

\author{
ANALYSIS OF THE PROVISION FOR IMPLEMENTATION OF REVERSE LOGISTICS IN \\ THE SUPERMARKET RETAIL
}

ANÁLISIS DE LA DISPOSICIÓN PARA LA IMPLEMENTACIÓN DE LA LOGÍSTICA
INVERSA EN LA VENTA AL POR MENOR DEL SUPERMERCADO

Sergio Silva Braga Junior ${ }^{1}$
Karina Tonelli Silveira Dias Junqueira $^{2}$
(D) Dirceu da Silva ${ }^{3}$
(D) Sandra Cristina Oliveira ${ }^{4}$

Cite as - American Psychological Association (APA)

Braga Junior, S. S., Junqueira, K. T. S. D., Silva, D., \& Oliveira, S. C. (2020, May/Aug.). Análise sobre a disposição para implementação da logística reversa no varejo supermercadista. International Journal of Innovation - IJI, São Paulo, 8(2), 204-222. https://doi.org/10.5585/iji.v8i2.17699.

\section{Resumo}

Objetivo do estudo: O objetivo da presente pesquisa foi o de analisar a disposição para implementação da logística reversa no varejo supermercadista.

Metodologia: Foram coletados os dados sobre a prática de logística reversa em 18 supermercados e utilizou-se a regressão logística para gerar um modelo de avaliação sobre a disposição para tal prática.

Originalidade/Relevância: Na literatura, não existem estudos que sugerem um modelo para implementação e orientação para a logística reversa. O modelo proposto no presente estudo pode ser aplicado em outras áreas do conhecimento.

Principais resultados: Como resultado, foi observado que, por meio das variáveis que definem as características do varejo, não é possível afirmar se um supermercado irá ou não implementar o processo da logística reversa.

Contribuições teóricas/metodológicas: $\mathrm{O}$ método utilizado pode ser empregado para construção de modelos de gestão e decisão, tanto para a indústria como para o varejo.

Contribuições sociais/para a gestão: Com base na presente pesquisa, as empresas podem aplicar o modelo para tomada de decisão sobre a viabilidade ou não da implementação da Logística Reversa.

Palavras-chave: Logística reversa. Varejo. Regressão logística.

\footnotetext{
${ }^{1}$ Universidade Estadual Paulista (UNESP), Tupã, São Paulo - Brasil. sergio.braga @ unesp.br

${ }^{2}$ Universidade Estadual de Campinas (UNICAMP), Limeira, São Paulo - Brasil. kaasdias@ gmail.com

${ }^{3}$ Universidade Estadual de Campinas (UNICAMP), Campinas, São Paulo - Brasil. dirceuds@ gmail.com

${ }^{4}$ Universidade Estadual Paulista (UNESP), Tupã, São Paulo - Brasil. sandra.oliveira@ unesp.br
} 


\section{Abstract}

Purpose: The objective of this research was to analyze the willingness to implement reverse logistics in supermarket retail.

Methodology: Data were collected on the practice of reverse logistics from 18 supermarkets and using logistic regression to generate a model for evaluating the disposition for such practice. Originality/Relevance: In the literature, there are no studies that suggest a model for implementation and guidance for reverse logistics, since the model proposed in the present study can be applied in other areas of knowledge.

Main results: As a result, it was observed that through the variables that define the characteristics of retail, it is not possible to say whether or not a supermarket will implement the reverse logistics process.

Theoretical/methodological contributions: The method used can be used to build management and decision models for both industry and retail.

Social/management contributions: Based on this research, companies can apply the model for decision making on the feasibility or not of implementing Reverse Logistics.

Keywords: Reverse logistics. Retail. Logistic regression.

\section{Resumen}

Objetivo del estudio: El objetivo de esta investigación fue analizar la disposición a implementar la logística inversa en el supermercado minorista.

Metodología: Se recopilaron datos sobre la práctica de la logística inversa de 18 supermercados y utilizando la regresión logística para generar un modelo para evaluar la disposición para dicha práctica.

Originalidad / Relevancia: En la literatura, no hay estudios que sugieran un modelo para la implementación y orientación para la logística inversa, ya que el modelo propuesto en el presente estudio puede aplicarse en otras áreas del conocimiento.

Resultados principales: Como resultado, se observó que a través de las variables que definen las características del comercio minorista, no es posible decir si un supermercado implementará o no el proceso de logística inversa.

Contribuciones teóricas / metodológicas: El método utilizado se puede utilizar para construir modelos de gestión y decisión para la industria y el comercio minorista.

Contribuciones sociales / de gestión: En base a esta investigación, las empresas pueden aplicar el modelo para la toma de decisiones sobre la viabilidad o no de implementar la logística inversa.

Palabras clave: Logística inversa. Al por menor. Regresión logística.

\section{Introdução}

O aumento da população e das atividades industriais, dados a partir da Revolução Industrial, são fatores que contribuíram para a ascensão no uso de recursos naturais e de produção. Do mesmo modo, a produção de resíduos cresceu e, com ela, agravou-se a situação ambiental do planeta, em virtude da disposição incorreta dos mesmos. Esses fatores deram origem à situação de responsabilidade social e superação ecológica, o que significa que se produz e consome mais do que a natureza pode absorver (Schor, 2010; Oliveira, Cândido \& 
Lima, 2019). Nesse sentido, surge a necessidade de criar fontes alternativas para lidar com os resíduos. Tais alternativas podem se dar por meio da redução, reutilização e práticas de reciclagem, nesta ordem de importância (Winandy \& Gallardo, 2014). Destaca-se que estas ações integram a política dos 3 R's, uma das práticas de gestão ambiental mais conhecidas e adotadas mundialmente (Winandy \& Gallardo, 2014; Naspolini Junior \& Guadagnin, 2014).

No meio empresarial, as questões ambientais ganham destaque, impulsionadas, principalmente, em função das pressões legais e sociais relativas ao meio ambiente. No entanto, os objetivos econômicos das organizações de obter maiores receitas para garantir sua participação no mercado, não são desprezados. Desse modo, a dimensão ambiental é incorporada na organização e passa a ser utilizada como estratégia competitiva, tanto na organização, como agente individual, quanto na cadeia de suprimentos.

Conforme apresentam Marchesini e Alcântara (2016), as atividades de logística reversa estão diretamente relacionadas à gestão de retornos, que consiste em um dos oito processoschave de negócios integrantes da Supply Chain Management - SCM, sendo: gestão de relacionamento com o cliente; gestão de serviço ao cliente; gestão de demanda; atendimento de pedidos; gestão do fluxo de manufatura; gestão de relacionamento com o fornecedor; desenvolvimento e comercialização do produto e gestão de retornos (Croxton et al., 2002). Estes processos, definidos pelo The Global Supply Chain Forum, abrangem tanto fluxos a jusante quanto a montante (Croxton et al., 2002).

A adoção de práticas de logística reversa é utilizada como uma ferramenta de gestão estratégica e dá origem a uma série de bons resultados percebidos nas esferas ambiental, econômica, social (Lacerda, 2002; Braga Junior, Merlo \& Nagano, 2009), competitiva (TibbenLembke, 1998) e de imagem e reputação da organização (Chaves et al., 2005; Chaves \& Batalha, 2006; Huang et al., 2015).

Esses resultados impulsionam a adoção da atividade pelas organizações, principalmente no setor varejista, por este ser um grande propagador de princípios e valores de responsabilidade social (Parente et al., 2009) e ambiental (Dias \& Braga Junior, 2016, APAS, 2015a), que estão intimamente ligadas. Acrescenta-se o aspecto legal como incentivo na adoção de práticas ambientais. Tratando-se de logística reversa, a Lei Federal 12.305/2010 institui a Política Nacional de Resíduos Sólidos (PNRS). Essa altera a Lei 9.605/1998 - Lei dos Crimes Ambientais, e aborda a responsabilidade compartilhada entre sociedade, organizações e entidades governamentais, no que se refere à promoção da logística reversa (Casa Civil, 2010). 
Tratando-se do segmento supermercadista, o descarte das embalagens dos produtos originados neste setor, contribui para a existência e multiplicação do lixo doméstico e urbano em geral, fazendo-se necessário o desenvolvimento de ações para diminuir os impactos causados ao meio ambiente. Ceretta e Froemming (2013) abordam que o varejo supermercadista, além de produtor é um repassador de produtos geradores de lixo doméstico, uma vez que grande parte dos resíduos da população é originada pelas mercadorias adquiridas por meio desse setor. Dentre os resíduos produzidos pelos supermercados pode-se citar: plástico, papelão, paletes e resíduos orgânicos, provenientes das embalagens dos produtos e de atividades operacionais em geral (Dias \& Braga Junior, 2016).

Nesse contexto, a logística reversa surge como uma oportunidade de ganho para o setor, uma vez que permite a reciclagem dos materiais originados nos supermercados e lhe confere bons resultados econômicos, ambientais e sociais. Dessa forma, o varejo supermercadista passa a assumir novas funções, como por exemplo, o comprometimento de reduzir o lixo gerado, a reciclagem e reutilização - 3 R's (Braga Junior \& Rizzo, 2014; Dias \& Braga Junior, 2016).

Portanto, o problema de pesquisa que orienta o presente trabalho é expresso pela seguinte questão: Como mensurar um modelo que permita avaliar a disposição para implementação da logística reversa no varejo? Nesse sentido, o objetivo foi o de analisar a disposição para implementação da logística reversa no varejo supermercadista. Com os dados coletados junto a 18 supermercados e utilizando a regressão logística, foi gerado o modelo de avaliação da disposição. Como resultado foi observado que, por meio das variáveis que definem as caracteristicas do varejo, não é possível afirmar se um supermercado irá ou não implementar o processo da logística reversa.

\section{Varejo supermercadista}

Kotler (2000, p. 541) apresenta a definição de supermercado como operações de autosserviços relativamente grandes, de baixo custo, baixa margem e altos volumes, projetadas para atender todas as necessidades de alimentação, higiene e limpeza doméstica dos consumidores.

Braga Júnior, Merlo e Nagano (2009) consideram o varejo supermercadista como um sistema de autosserviço, que dispõe de uma variedade de 4.000 a 14.000 produtos, que são diversificados em itens alimentícios e não alimentícios, havendo pelo menos dois check-outs e área útil de venda entre $300 \mathrm{~m}^{2}$ e $5.000 \mathrm{~m}^{2}$, fracionada em seções como mercearia, açougue, produtos de limpeza, entre outros. Ainda disponibilizam para seus consumidores carrinhos e 
cestas, não sendo necessária a presença de um vendedor. Outra característica importante desse setor está no alto giro de produtos, porém com baixas margens de lucro (Kotler, 2000; Saab \& Gimenez, 2000).

Não obstante, esse setor passa por intensas transformações ao longo dos anos. Dentre os principais motivos que originam tais mudanças, destacam-se: a influência administrativa de aquisições e fusões; as alterações no cenário empresarial, que é altamente competitivo; e a influência da sociedade, que está cada vez mais consciente da escassez de recursos naturais (Parente et al., 2009, Delgado, 2014, Braga Junior \& Rizzo, 2014). Essas mudanças conferem responsabilidades sociais e ambientais ao setor, o que obriga os gestores a repensarem suas estratégias e atuarem em conformidade com as demandas legais e sociais. Destaca-se ainda as mudanças tecnológicas no setor. Um exemplo é o Amazon Retail que opera como um mediador de vendas on-line, oferecendo planos profissionais e individuais, por meio dos quais obtém suas receitas.

As empresas supermercadistas são responsáveis por disseminar princípios e valores de responsabilidade social e de sustentabilidade, de modo a sensibilizar e educar consumidores, funcionários e fornecedores para a adoção de hábitos e práticas sustentáveis (APAS, 2015a). Nesse sentido, como uma iniciativa relevante para o tratamento das questões ambientais no varejo de supermercados, a Associação Paulista de Supermercados - APAS lançou o Guia Prático APAS: Supermercado Sustentável, e o Guia da Loja Verde. Nos quais são apresentadas orientações sobre questões relacionadas a diversos assuntos ambientais, dentre os quais: avaliação dos impactos sociais e ambientais de sua operação; consumo de água e energia; gestão de resíduos e uso de sacolas (APAS, 2015a; APAS, 2015b).

Contudo, é na dimensão ambiental que se encontra o maior gargalo da atuação dos supermercados. Apesar de não gerar tanto impacto ao meio ambiente, comparado às atividades industriais, as compras supermercadistas e as embalagens derivadas dessas compras resultam em uma quantidade de lixo significativa, o que faz com que o varejo seja, além de produtor, um repassador de produtos geradores de lixo doméstico (Ceretta \& Froemming, 2013).

Desse modo, evidencia-se o papel do varejo supermercadista como propagador da geração do lixo doméstico, o qual dá origem a uma poluição ambiental significativa. Concomitantemente, os supermercados possuem uma participação essencial na busca de alternativas à disposição inadequada dos resíduos e no desenvolvimento de ações minimizadoras da produção de lixo e mitigadoras dos impactos causados por este (Ceretta \& Froemming, 2013). 
Gallardo et al. (2013) e Winandy e Gallardo (2014) destacam que a preocupação ambiental no varejo supermercadista é mais evidente internacionalmente e, inclusive, propagaram essa preocupação ao longo da SCM, enquanto que, no Brasil, esta é uma questão em fase de desenvolvimento e que avança ao longo dos anos.

Dentre as ações de práticas ambientalmente corretas, realizadas entre as empresas do seguimento supermercadista, estão incluídas: a utilização de embalagens recicláveis, o incentivo à prática da coleta seletiva de lixo, a prevenção do desperdício de recursos naturais, como água e energia elétrica, o uso de sacolas retornáveis e biodegradáveis, a criação de locais para coleta de pilhas e lâmpadas usadas, o estabelecimento de práticas de logística reversa, entre outras (Parente et al., 2009; Ceretta \& Froemming, 2013; Dias \& Braga Junior, 2016).

Conforme articulam Braga Junior e Rizzo (2014), no setor do varejo supermercadista, a logística reversa surge como uma nova possibilidade de ganho, uma vez que esta prática auxilia no desempenho da organização e gera possibilidades de aproveitamento do que seria descartado. Nesse sentido, a logística reversa oferece a oportunidade de reciclagem de diversos resíduos provenientes do setor como, por exemplo: papel, papelão, plástico, paletes, resíduos orgânicos e outros, resultantes das embalagens primárias, secundárias e terciárias dos produtos e de suas atividades operacionais em geral (Dias \& Braga Junior, 2016).

Segundo a Associação Brasileira de Embalagens (ABRE), são consideradas embalagens primárias aquelas que estão diretamente em contato com o produto; embalagens secundárias, as que são designadas para conter uma ou mais embalagens primárias, podendo não ser indicadas para o transporte e embalagens terciárias aquelas que agrupam diversas embalagens primárias ou secundárias para a realização de transporte (ABRE, 2008). Em vista disso, a implementação da logística reversa no setor supermercadista contribui para a redução dos impactos ambientais e sociais, originados por meio do descarte inadequado dos resíduos gerados pelos supermercados.

De fato, o varejo supermercadista vem aumentando sua responsabilidade perante o consumidor e o meio ambiente. Tal responsabilidade desdobra-se na gestão do lixo originado por produtos e embalagens advindos dos supermercados, que se torna um grande inimigo para o meio ambiente. Braga Junior, Merlo e Nagano (2009), Braga Junior e Rizzo (2010) e de Winandy e Gallardo (2014) demonstram que os resíduos que mais são gerados pelos supermercados correspondem às embalagens de plástico e papelão, provenientes das entregas de produtos para revenda nas lojas. Segundo dados do DataMark as embalagens provenientes 
destes materiais recebem destaque também na indústria, sendo que as principais são as produzidas e utilizadas em diversos setores do supermercado (Datamark, 2017).

Além dos supermercados, a nível nacional, estes resíduos são muito presentes no varejo em geral, fator que lhes confere destaque para este estudo. As especificações destas embalagens, quanto às questões ambientais e de ciclo de destino dado a partir do varejo supermercadista, são abordadas nos tópicos seguintes.

\section{Logística reversa no varejo}

Historicamente, o varejo originou-se de vendas informais que ocorriam nas ruas das cidades, passando, posteriormente, para armazéns e empórios, que vendiam produtos duráveis e não duráveis. O crescimento da indústria e a criação de produtos padronizados, fatos ocorridos a partir da Revolução Industrial, impulsionaram o aumento do número de estabelecimentos comerciais, originando, adiante, as grandes casas de autosserviços (Senhoras, 2003).

O setor varejista, definido por Parente (2000, p. 22) como "todas as atividades que englobam o processo de venda de produtos e serviços a uma necessidade pessoal do consumidor final", possui atributos que lhe conferem a característica de ser um grande propagador de princípios e valores de responsabilidade social (Parente et al. 2009) e ambiental (Dias \& Braga Junior, 2016).

Parente et al. (2009) articulam que estas características estão relacionadas a: (i) proximidade com o consumidor final e a articulação social nas comunidades em que está inserida; (ii) influência do varejo na cadeia de suprimentos, uma vez que o setor é capaz de operar como intenso agente modificador de toda a cadeia, no sentido de promover e estimular a realização de ações sociais e ambientais; (iii) sua representatividade geográfica, visto que existem lojas varejistas em todas as regiões, cidades, municípios.

Esta posição do setor permite que o mesmo realize ações em prol da sustentabilidade. Estas são ressaltadas por Parente et al. (2009) e dizem respeito a ações internas, como o controle da gestão de impactos sociais e ambientais em suas lojas, e ações externas, no que tange ao incentivo do varejo sobre seus fornecedores e clientes a produzir e consumir produtos sustentáveis, bem como realizar o descarte correto dos mesmos e de seus resíduos.

Contudo, o fluxo reverso, em sua complexidade, exige que o varejista esteja preparado para tomar decisões do que fazer com o produto retornado, baseando-se no que for mais lucrativo para a organização, ou estabelecido em contrato com fornecedores. Esta questão se torna um pouco mais complicada devido à dificuldade em prever os retornos. Tibben-Lembke 
e Rogers (2002) justificam que, enquanto o fluxo direto é previsto por meio de estudos de previsão de demanda, o fluxo reverso é reativo, pois, para que o fluxo seja iniciado, depende de ações de outros agentes, como o consumidor ou outros membros a jusante da SCM. Vlachos (2014) adiciona que, o fato de a logística reversa ocorrer de modo reativo, torna limitada a visão estratégica sobre a atividade e a capacidade das organizações em atender as demandas dos consumidores. A Figura 1 representa o fluxo da logística tradicional e reversa no varejo, segundo os autores referenciados na mesma.

Destaca-se ainda que a quantidade de materiais retornados ao varejo é relativamente baixa e muito diversificada. Este fator influencia no valor do produto vendido, uma vez que baixos volumes implicam em preços relativamente menores (Tibben-Lembke \& Rogers, 2002). Por tal motivo, é preciso avaliar os custos e receitas incorridos sobre a atividade de logística reversa, de modo a verificar se é compensatória ou não.

Figura 1 - Fluxo da logística tradicional e logística reversa no varejo
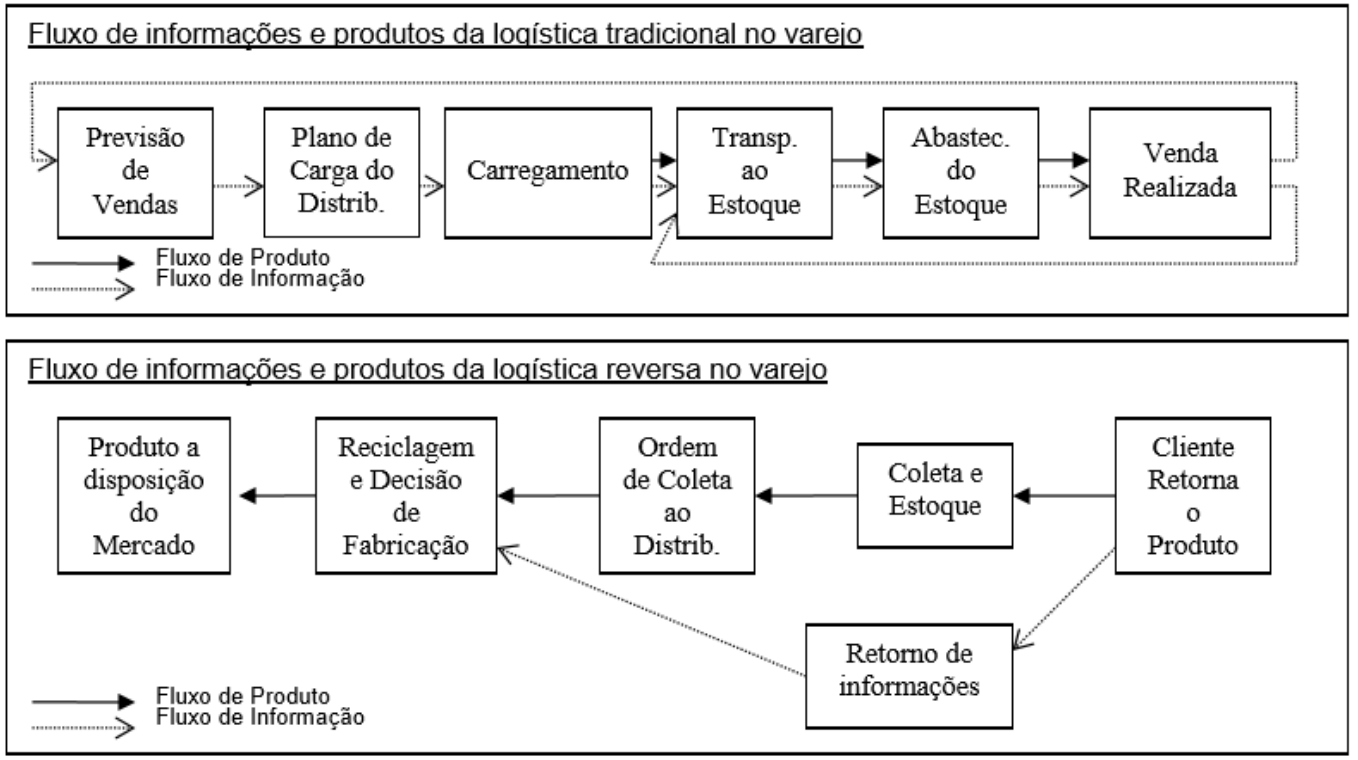

Fonte: Braga Junior e Rizzo (2010, p. 115) adaptado de Tibben-Lembke e Rogers (2002, p. 273).

O processo da logística reversa, independentemente do setor a qual se aplica, envolve a participação de todos os elos da SCM para que o retorno à cadeia seja concretizado, adicionando-se o mercado secundário em alguns casos (Braga Junior, Merlo \& Nagano, 2009). No entanto, podem ocorrer variações quanto à execução do retorno e aos agentes envolvidos, dadas pelo tipo de produto retornado e a SCM a qual ele está inserido. Assim, não pode ser dito que há uma generalização/padronização quanto à execução da logística reversa. 
Em virtude desta diferenciação das atividades de logística reversa, segundo o produto e sua respectiva SCM, o setor varejista, portanto, não deve ser generalizado, uma vez que o mesmo conta com diversos tipos de estabelecimento e comércios, diferenciando-se segundo seu tamanho, público-alvo e produto/serviço ofertado. Assim, supõe-se que a execução das atividades de logística reversa é diferenciada segundo as particularidades do setor. Delgado (2014) articula que dentre os diversos tipos de estabelecimentos varejistas, destacam-se as lojas especializadas; lojas de departamentos; supermercados; lojas de conveniência; lojas de desconto e superlojas.

Winandy e Gallardo (2014) evidenciam que o setor supermercadista é um segmento de destaque e ocupa posição de liderança no varejo quanto à venda de produtos de grande consumo no país (como alimentos, utensílios domésticos, produtos de higiene pessoal e limpeza, por exemplo), o que lhe conferiu representação de mais de $40 \%$ do setor de comércio no ano de 2012, sendo este estudo o mais recente encontrado na literatura. Essa posição de destaque, lhe atribui uma série de responsabilidades que exigem de seus gestores novas formas de agir e pensar a organização, principalmente quando se trata do descarte de produtos e da produção de lixo doméstico, que também faz parte do conceito de cidades sustentáveis (Ceretta \& Froemming, 2013; Kobayashi, Kniess, Serra, Ferraz \& Ruiz, 2017).

\section{Procedimentos metodológicos}

Para atingir o objetivo proposto foi realizada uma pesquisa de caráter quantitativo utilizando os dados coletados junto a 18 supermercados. Em cada uma das lojas, o gerente foi entrevistado para levantar as características das lojas e o quanto ele e sua equipe estavam envolvidos com o processo de logística reversa. A partir daí, foi atribuído um valor de "sim" ou "não" sobre a disposição para a implementação da logística reversa.

Sendo assim, para analisar este aspecto, a ferramenta estatística mais adequada é a Regressão Logística, pois, a mesma é utilizada quando a variável dependente é binomial (discreta). Esse modelo permite estudar se a variável discreta depende ou não de outras variáveis (Martins \& Domingues, 2011; Montgomery, Peck \& Vining, 2012).

Utilizando o software SPSS 22.0, a Regressão Logística Múltipla foi aplicada para testar a disposição (chance) de implementação da logística reversa frente às variáveis - área de venda, área de logística reversa, ticket médio, número de check-outs e fluxo médio de pessoas, sendo que estas variáveis são as variáveis utilizadas para definir o porte do supermercado. 
O modelo de regressão logística múltiplo considera um conjunto de $k$ variáveis independentes, que podem ser numéricas ou não, ao prever a probabilidade da variável resposta $Y$. Este modelo é expresso por:

$$
Y=\beta+\beta x_{1}+\beta x_{2}+. \beta x_{k}+\varepsilon \text {. }
$$

Assim, pela definição de valor esperado, a média condicional para dados dicotômicos será dada por $E(Y \mid \mathbf{X}=\mathbf{x})=\pi(\mathbf{x})$. Logo,

$$
\left.\mathcal{H}(Y X)=\beta+\beta x_{1}+\beta x_{2}+.+\beta x_{k}=\alpha\right) \text { (X). }
$$

Como $\mathcal{E}(Y \mid X \Rightarrow \mathbf{X}$ deve estar entre zero e um, ou seja,

$$
\begin{gathered}
0 \leq E(Y \mid \mathbf{X}=\mathbf{x}) \leq 1 \\
0 \leq \beta+\beta x_{1}+\beta_{2} x_{2}+.+\beta x_{k} \leq 1
\end{gathered}
$$

Desta forma, quando a variável resposta for qualitativa binária o erro $\varepsilon=1-\mathcal{A}(\mathbf{x}$ não tem distribuição normal e a variância é heterogênea, pois o mesmo pode assumir um dos dois valores:

$$
\begin{gathered}
Y=1 \Rightarrow \varepsilon=1-\pi(\mathbf{x}) \text { com probabilidade } \pi(\mathbf{x}) \\
Y=0 \Rightarrow \varepsilon=-\pi\left(\mathbf{x}^{\prime} \text {, com probabilidade } 1-\pi(\mathbf{x})\right.
\end{gathered}
$$

Para garantir que a resposta $Y$ seja expressa como uma probabilidade se faz necessário o uso de uma função de ligação entre $\pi(\mathbf{x})$ e o preditor linear $\beta_{0}+\beta_{1} x_{1}+\beta_{2} x_{2}+$. $+\beta_{k} x$. A utilização desta função permite a linearização da função logística, que frequentemente possui função resposta curvilínea e, desta forma, encontra-se a resposta média que é a probabilidade de ocorrência do evento (Montgomery, Peck \& Vining, 2012). Neste trabalho foi utilizada a função de ligação logit, também chamada de transformação logit da probabilidade $\pi(\mathbf{x})$, que satisfaz:

$$
1\left\{\begin{array}{l}
\mathrm{A}(\mathrm{x}) \\
1-\mathcal{A}(\mathrm{x})
\end{array}\right\}=\beta+\beta x_{1}+\beta_{2} x_{2}+.+\beta x_{i}
$$

Expressando-a em termos de preditor linear, tem-se (Corrar, et al., 2009): 


$$
\lambda(\mathbf{x})=\frac{e^{\beta+\beta x_{1}+\beta_{2} x_{2}+.+\beta_{k} x_{k}}}{1+e^{\beta+\beta_{1} x_{1}+\beta_{2} x_{2}++\beta_{k} x_{k}}}
$$

Assim, o modelo de regressão logística múltiplo resume-se a $Y=E(Y \mid X=\mathbf{x})+\varepsilon$, onde $E(Y \mid \mathbf{X}=\mathbf{x})=\pi(\mathbf{x})=\frac{e^{\beta_{0}+\beta_{1} x_{1}+\beta_{2} x_{2}+.+\beta_{k} x_{k}}}{1+e^{\beta_{0}+\beta_{1} x_{1}+\beta_{2} x_{2}+.+\beta_{k} x_{k}}}$.

O termo $\ln \left\{\frac{\pi(\mathbf{x})}{1-\pi(\mathbf{x})}\right\}$ em (6) é denominado resposta média logit, onde a razão $\frac{\pi(\mathbf{x})}{1-\pi(\mathbf{x})}$ é chamada de chance (odds). Particularmente, se $x=x_{j}$ tal que chan $(\xi) \frac{\pi\left(x_{j}\right)}{1-\pi\left(x_{j}\right)}$ e se $x=x_{j}+1$ tal que $\left.c h a \eta_{j} \mathcal{G}_{1}\right)=\frac{\pi\left(x_{j}+1\right)}{1-\lambda\left(x_{i}+1\right)}$, então, a razão entre a chance de um evento ocorrer em um grupo $\left(\right.$ chance $\left._{(j+1)}\right)$ e deste evento ocorrer em outro grupo $\left(\right.$ chance $\left._{(j)}\right)$ é chamada de razão de chances (odds ratio) e é dada por

$$
O R=\frac{c h a_{(j+1)} c e^{h_{\beta_{j}}}}{c h a_{(y)} c e^{\beta_{j}}}, j=1,2, \ldots, k
$$

A aplicação do método de máxima verossimilhança consiste em, primeiramente, construir uma função chamada de função de verossimilhança. As estimativas dos parâmetros desconhecidos são escolhidas de forma que maximizem esta função e estas são denominadas estimativas de máxima verossimilhança. Deste modo, as estimativas resultantes ficam muito próximas dos dados observados.

Assim, dada uma amostra aleatória composta por $n$ pares de observações $\left(X_{i}, Y_{i}\right), i=1,2, \ldots, n$, onde $Y_{i}$ representa os valores observados da variável resposta e $X_{i}$ representa os valores observados de $k$ variáveis independentes, uma forma conveniente para expressar a contribuição da função de verossimilhança para os pares $\left(X_{i}, Y_{i}\right)$ é dada por:

$$
F\left(x_{i}\right)=\left[\pi\left(x_{i}\right)\right]^{y_{i}}\left[1-\pi\left(x_{i}\right)\right]^{1-y_{i}}
$$

Desde que assumido que as observações são independentes, a função de verossimilhança é obtida como o produto dos termos dados na expressão anterior (Montgomery, Peck \& Vining, 2012): 


$$
L(\boldsymbol{\beta})=\prod_{i=1}^{n} F\left(x_{i}\right)=\prod_{i=1}^{n}\left[\pi\left(x_{i}\right)\right]^{y_{i}}\left[1-\pi\left(x_{i}\right)\right]^{1-y}
$$

onde $\boldsymbol{\beta}=\left(\beta_{0}, \beta_{1}, \ldots, \beta_{k}\right)$. Para facilitar os cálculos, aplica-se o logaritmo natural nesta função (log-verossimilhança), obtendo-se:

$$
1 \quad L(\boldsymbol{\beta})=\sum_{i=1}^{n} y_{i}\left(\beta_{0}+\beta_{1} x_{1}+\beta_{2} x_{2}+.+\beta_{k} x_{k}\right)-\sum_{i=1}^{n}\left(11+e^{\beta_{i}+\beta_{1} x_{1}+\beta_{2} x_{2}++}+\beta_{k} x_{k}\right.
$$

que será maximizada se $\frac{\partial 1 \mathrm{n} L(\boldsymbol{\beta})}{\partial \boldsymbol{\beta}}=0$. Assim, por meio de métodos numéricos chegase às estimativas de máxima verossimilhança. Quando obtidas, tais estimativas devem ser substituídas em (10) para obter a função resposta ajustada.

A sistematização e a análise estatística dos dados foram realizadas por meio de Planilhas do Microsoft Excel e do SPSS 22.0. Este último calcula um modelo ajustado e otimizado para o método de regressão logística múltiplo, utilizando um algoritmo iterativo para obter as estimativas dos parâmetros de interesse.

O processo de seleção de variáveis preditoras para um modelo de regressão foi feito por meio de testes de hipóteses da existência dos parâmetros $\beta_{0}, \beta_{1}, \beta_{2}, \ldots, \beta_{k}$. O procedimento consiste em testar a hipótese nula de que certo parâmetro é igual a zero. Se esta for rejeitada, para um nível de significância $\alpha$ estabelecido, então, pode-se afirmar que há evidências de que uma determinada variável independente influencia na variável resposta. Uma vez definido o modelo e obtidas as estimativas dos parâmetros deste, é necessário avaliar a qualidade do ajuste do modelo aos dados, com base em medidas que podem ser calculadas mediante as funções de ligação e de máxima verossimilhança.

Os testes de aderência (goodness-of-fit tests) permitem avaliar a qualidade dos resultados obtidos, ou seja, a validação do ajustamento do modelo. Aqui é testada a hipótese nula de que o ajuste do modelo aos dados é bom versus a hipótese de que o ajuste é ruim. Os métodos mais usuais, baseados na distribuição qui-quadrado, são: Pearson (verifica o quanto as observações são satisfatoriamente previstas pelo modelo); Deviance (compara o logaritmo da verossimilhança do modelo ajustado com o logaritmo da verossimilhança do modelo completo); e Hosmer-Lemeshow (avalia o modelo ajustado verificando se as frequências observadas e frequências esperadas da variável resposta estão próximas).

Se o $p$-valor para os testes descritos anteriormente estiver entre 0,37 e 0,85 indica que não há evidências suficientes de que o modelo não se ajusta aos dados adequadamente, ou ainda, 
se $p$-valor $\leq \alpha$, rejeita-se a hipótese $H_{0}$ de que o ajuste do modelo é apropriado (Montgomery, Peck \& Vining, 2012).

Quando uma ou mais variáveis explicativas são quantitativas, os dados costumam ser dispersos demais para o uso dos testes de aderência de Pearson e de Deviance. Nesta situação, o resultado obtido com o teste de Hosmer-Lemeshow fornecerá melhores resultados.

Pode-se verificar a qualidade do ajuste do modelo por meio de alguns índices de correlação de postos, sendo os mais utilizados: índice $D$ de Somers, índice Gamma de Goodman-Kruskal e índice Tau-a de Kendall. Estes índices variam entre zero e um e, quanto maior forem seus valores, melhor será a capacidade preditiva do modelo estimado.

\section{Análise e discussão dos resultados}

As lojas que fizeram parte da pesquisa encontram-se distribuídas no interior do estado de São Paulo. Suas características de área (venda, armazenagem e logística reversa), check outs, fluxo médio de pessoas/dia e ticket médio do mês de outubro de 2017 estão apresentadas na tabela 1 .

Tabela 1 - Caracterização das 18 lojas visitadas

\begin{tabular}{lccccc}
\hline & No de & Fluxo médio de & Ticket & \multicolumn{2}{c}{ Área $\left(\mathbf{m}^{2}\right)$} \\
\cline { 5 - 6 } & check outs & pessoas/dia & $\begin{array}{c}\text { médio/mensal } \\
\text { outubro }\end{array}$ & Venda & $\begin{array}{c}\text { Logística } \\
\text { reversa }\end{array}$ \\
\hline Loja 02 & 10 & 2.000 & $\mathrm{R} \$ 38,00$ & 1.000 & 10 \\
\hline Loja 03 & 06 & 1.000 & $\mathrm{R} \$ 70,00$ & 1.000 & 10 \\
\hline Loja 04 & 14 & 3.000 & $\mathrm{R} \$ 48,00$ & 3.000 & 15 \\
\hline Loja 05 & 05 & 900 & $\mathrm{R} \$ 25,00$ & 800 & 10 \\
\hline Loja 07 & 09 & 900 & $\mathrm{R} \$ 53,00$ & 800 & 10 \\
\hline Loja 08 & 08 & 1.230 & $\mathrm{R} \$ 26,00$ & 1.000 & 7 \\
\hline Loja 09 & 12 & 1.450 & $\mathrm{R} \$ 50,00$ & 1.250 & 10 \\
\hline Loja 10 & 13 & 2.000 & $\mathrm{R} \$ 66,00$ & 1.800 & 15 \\
\hline Loja 11 & 10 & 1.660 & $\mathrm{R} \$ 49,00$ & 1.000 & 10 \\
\hline Loja 12 & 12 & 3.500 & $\mathrm{R} \$ 140,00$ & 1.800 & 15 \\
\hline Loja 13 & 08 & 1.256 & $\mathrm{R} \$ 34,00$ & 1.000 & 10 \\
\hline Loja 14 & 18 & 2.500 & $\mathrm{R} \$ 56,00$ & 2.000 & 20 \\
\hline Loja 18 & 12 & 3.800 & $\mathrm{R} \$ 52,00$ & 1.900 & 15 \\
\hline Loja 20 & 18 & 2.000 & $\mathrm{R} \$ 250,00$ & 2.500 & 8 \\
\hline Loja 21 & 10 & 2.500 & $\mathrm{R} \$ 62,00$ & 1.300 & 10 \\
\hline & & & & & \\
\hline
\end{tabular}




\begin{tabular}{llcccc}
\hline Loja 25 & 10 & 900 & $\mathrm{R} \$ 55,00$ & 1.500 & 20 \\
\hline Loja 26 & 11 & 1.900 & $\mathrm{R} \$ 68,00$ & 2.000 & 16 \\
\hline Loja 27 & 07 & 1.100 & $\mathrm{R} \$ 35,00$ & 1200 & 17 \\
\hline
\end{tabular}

Fonte: Elaborado pelos autores.

Com base no número de check outs e na área de venda, observa-se que a rede possui lojas supermercadistas convencionais, que contam com uma média de 7 a 20 chek outs e área de venda de 700 a $2.500 \mathrm{~m}^{2}$ conforme Parente (2000, p. 30).Quanto ao público atendido pelas lojas, identifica-se que este é variado. Assim, pode-se inferir que as mesmas abrangem todas as classes sociais, de A à E. Esta informação foi inferida com base no que foi abordado pelos gerentes ao longo das visitas, assim como no fluxo de pessoas e ticket médio. Deve ser ressaltado que todas as lojas separam os materiais reciclados para a realização da prática de logística reversa, mas que durante a pesquisa foi observada a existência de vários casos que deixaram claro que se houvesse a possibilidade de não fazer, não fariam e que só praticam por ser politica da rede que participam.

Os dados coletados foram inseridos para serem analisados a partir da seguinte hipótese $H_{0}:$ A disposição (chance) para a prática da logística reversa no varejo está relacionada às caracteristicas de porte do supermercado.

Dando sequência, a regressão logística foi rodada pelo método do stepwise (Wald) no qual o software vai "colocando e retirando" as variáveis no modelo e testando a significância de explicação de cada uma delas. Ao final, são apresentadas apenas as variáveis independentes significativas que compõem o modelo (tabela 2) e que atendem aos critérios de qualidade geral de ajuste (tabela 3).

Tabela 2 - Modelo de Regressão Logística Ajustado

\begin{tabular}{lccccccrc}
\hline & & & & & & \multicolumn{3}{c}{ 95\% C.I. para EXP(B) } \\
\cline { 7 - 9 } Variável(is) inserida(s) & B & E.P. & Wald & gl & Sig. & $\operatorname{Exp}(\mathbf{B})$ & Inferior & Superior \\
\hline Area Logística Reversa $\left(\mathrm{m}^{2}\right)$ & $-0,441$ & 0,194 & 5,163 & 1 & 0,023 & 0,644 & 0,440 & 0,941 \\
Constante & 5,817 & 2,514 & 5,354 & 1 & 0,021 & 335,905 & & \\
\hline
\end{tabular}

Fonte: Elaborado pelos autores.

Considerando o modelo ajustado, a estatística apresentada demonstra que o modelo atende aos critérios de qualidade (tabela 3). 
Tabela 3 - Qualidade de ajuste do modelo

\begin{tabular}{lr}
\hline \multicolumn{2}{c}{ Sumarização do modelo } \\
\hline Log da Verossimilhança -2* & 16,662 \\
R quadrado Cox \& Snell & 0,361 \\
R quadrado Nagelkerke & 0,484 \\
Teste de Hosmer e Lemeshow** & 1,550 \\
Testes de Omnibus de Coeficientes do Modelo*** & 8,068
\end{tabular}

Fonte: Dados da pesquisa.

* Estimação finalizada no número de iteração 5 porque as estimativas de parâmetro mudaram foram alteradas para menos de 0,001 .

** Significância de $0,671(\mathrm{p}>0,05)$

*** Significância de $0,005(\mathrm{p}<0,05)$

Após avaliar o modelo e a qualidade de ajuste do modelo é gerada a equação de regressão logística. Por meio desta equação pode-se avaliar a propabilidade de chance (disposição) de um supermercado passar a praticar a logística reversa.

$$
P_{L R}=\frac{1}{\left.\left.1+e^{-(5,817+(-0,441 \times \text { Área }} L R\right)\right)}
$$

Considerando que a única variável independente que ficou na equação foi a área dedicada à logística reversa, não significa que quanto maior a área maior a chance de prática, pois, ao analisar o valor do coeficiente de estimação $(\operatorname{Exp}(B))$ apresentado na tabela 2, a chance de acontecer, com base nesta equação é de $0,356(35,6 \%)$, visto que este, varia de 0 até 1 e o calculo é baseado no valor inteiro menos o coeficiente de estimação (1-Exp(B)).

\section{Considerações finais}

A prática da logística reversa vem se tornando cada mais forte no varejo supermercadista que tem olhado para os resíduos como uma fonte alternativa de receita ou como uma fonte alternativa de redução do custo operacional. Tem sido comum encontrar varejistas separando, principalmente o plástico e o papelão para serem vendidos dentro da cadeia de resíduos destinados à reciclagem ou reutilização.

Mesmo quando isso não acontece, são formadas parcerias com empresas ou cooperativas terceirizadas, que atuam na cadeia de resíduos destinados à reciclagem ou reutilização, em troca de serviços prestados ao varejista daquele determinado supermercado.

Sendo assim, esperava-se propor um modelo prático de avaliação de disposição para a prática da logística reversa com base nas características dos supermercados com maior 
propabilidade de chance de acontecer e assim, poder aceitar a hipotese $\mathrm{H}_{0}$ proposta nesta pesquisa.

Com os resultados e apesar do modelo estar estatísticamente ajustado em condições de se aceitar a hipotese $\mathrm{H}_{0}$, a mesma deve ser rejeitada, pois, as características que definem o porte do varejo, não são suficientes para explicar a disposição, visto que nenhuma delas ficou ajustada no modelo final e, consequentemente, na equação.

A pesquisa acabou demonstrando que, na prática, a definição sobre implementar a logística reversa fica a critério da política da rede de supermercados ou do varejista (caso não esteja inserido em uma rede).

Uma limitação da presente pesquisa, foi o fato da amostra contar com poucos supermercados, visto que uma amostra maior e de maior abrangência geográfica poderá trazer resultados mais expressivos.

Como sugestão de outras pesquisas, uma avaliação dos fatores motivadores para a implementação da prática de logística reversa para medir a disposição, pode ser a chave para criar de um modelo que reflita de forma precisa a realidade de mercado e a possibilidade de se melhorar os processos.

\section{Referências}

Associação Paulista de Supermercados (APAS). (2015a). Guia da Loja Verde. Disponível em: http://www.portalapas.org.br/m5.asp?cod_noticia=14870\&cod_pagina=1222. Acesso em: 15 set. 2015a.

Associação Paulista de Supermercados (APAS). (2015b). Guia Prático APAS: Supermercado Sustentável. Disponível em: http://varejosustentavel.com.br/painel/dbarquivos/dbanexos/guiaprticoapassupermercadosu stentvelp.pdf. Acesso em: 04 abr. 2015 b.

Braga Junior, S. S., \& Rizzo, M. R. (2010). Sustentabilidade através do aproveitamento de resíduos: um estudo dos processos implantados por um supermercado de médio porte/sustainability through the utilization of waste: a study of procedures implemented in a supermarket for medium size. Revista Brasileira de Engenharia de Biossistemas, 4(2), 108125 .

Braga Junior, S. S., Merlo, E. M., \& Nagano, M. S. (2009). Um estudo comparativo das práticas de logística reversa no varejo de médio porte. Revista da Micro e Pequena Empresa, 3(2), 64-81.

Buono, P. H. D. O., Dias, K. T. S., \& Braga Júnior, S. S. (2017). A gestão de resíduos de uma oficina de manutenção de veículos pesados: Um estudo da logística reversa para as sobras de aço. Revista GEPROS, 12(3), 179. 
Casa Civil. (2010). Lei $\mathrm{N}^{\circ} 12.305$, de 2 de agosto de 2010. Institui a política nacional de resíduos sólidos; altera a Lei no 9.605, de 12 de fevereiro de 1998; e dá outras providências. Disponível em: http://www.planalto.gov.br/ccivil_03/_ato20072010/2010/lei/112305.htm. Acesso em: 15 set 2016a.

Ceretta, S. B., \& Froemming, L. M. S. (2013). O Papel dos Supermercados na etapa da geração e descarte do lixo e o reflexo na questão ambiental. Desenvolvimento em Questão, 11(24), 235-259.

Chaves, G. D. L. D., \& Batalha, M. O. (2006). Os consumidores valorizam a coleta de embalagens recicláveis? Um estudo de caso da logística reversa em uma rede de hipermercados. Gestão \& Produção, 13(3), 423-434.

Chaves, G. D. L. D., Martins, R. S., JUNIOR, W., \& OPAZO, M. A. (2005). Diagnóstico da logística reversa na cadeia de suprimentos de alimentos processados no oeste paranaense (Tese de Doutorado, Universidade Estadual do Oeste do Paraná.).

Compromisso Empresarial Para Reciclagem (CEMPRE). (2015). Coleta seletiva ainda é um desafio para o país, aponta Ciclosoft 2016. São Paulo. Disponível em:

http://cempre.org.br/cempre-informa/id/70/coleta-seletiva-ainda-e-um-desafio-para-o-pais-aponta-ciclosoft-2016. Acesso em: 1 nov. 2016.

Compromisso Empresarial Para Reciclagem (CEMPRE). (2015). Composto Urbano. Disponível em: http://cempre.org.br/artigo-publicacao/ficha-tecnica/id/10/compostourbano. Acesso em: 05 out. 2015a.

Compromisso Empresarial Para Reciclagem (CEMPRE). (2015). Material Reciclável. Disponível em: http://cempre.org.br/cempre-informa/id/9/preco-do-material-reciclavel. Acesso em: 27 nov. 2017a.

Compromisso Empresarial Para Reciclagem (CEMPRE). (2015). Papel Ondulado. Disponível em: http://cempre.org.br/artigo-publicacao/ficha-tecnica/id/3/papel-ondulado. Acesso em: 05 out. 2015 b.

Compromisso Empresarial Para Reciclagem (CEMPRE). (2015). Política Nacional de Resíduos Sólidos - Agora é lei: Novos desafios para poder público, empresas, catadores e população. São Paulo. p.1-4. Disponível em http://www.cempre.org.br/busca/política\%20nacional\%20de\%20resíduos\%20sólidos. Acesso em: 05 out. 2015d.

Cooper, D. R., \& Schindler, P. S. (2016). Métodos de Pesquisa em Administração-12 ${ }^{a}$ Edição. McGraw Hill Brasil.

Croxton, K. L., Lambert, D. M., García-Dastugue, S. J., \& Rogers, D. S. (2002). The demand management process. The International Journal of Logistics Management, 13(2), 51-66.

Delgado, F. S. (2014). Análise da evolução da concentração no varejo supermercadista brasileiro entre 1998 e 2013. Trabalho de Conclusão de Curso, UFRS. 
Dias, K. T. S., Junior, S. S. B., \& Martinez, M. P. (2016). Reverse Logistics Analysis and Results Applied to the Grocery Retail. International Business Management, 10(18), 44034410.

Dias, K. T., \& Braga Junior, S. S. (2016). The use of reverse logistics for waste management in a Brazilian grocery retailer. Waste Management \& Research, 34(1), 22-29.

Gallardo, A. L. C. F., Winandy, A. J. C., de Siqueira, J. P. L., \& Junior, F. H. (2017). Sustentabilidade no setor supermercadista: estudo comparativo de grandes redes no brasil e no exterior. HOLOS, 5, 283-302.

Huang, Y. C., Rahman, S., Wu, Y. C. J., \& Huang, C. J. (2015). Salient task environment, reverse logistics and performance. International Journal of Physical Distribution \& Logistics Management, 45(9/10), 979-1006.

Kobayashi, A. R. K., Kniess, C. T., Serra, F. A. R., Ferraz, R. R. N., \& Ruiz, M. S. (2017). Smart sustainable cities: bibliometric study and patent information. International Journal of Innovation, 5(1), 77-96. Doi:10.5585/iji.v5i1.159

Kotler, P. (2000). Administração de marketing.. Editora Prentice Hall, São Paulo.

Lacerda, L. (2002). Logística reversa: uma visão sobre os conceitos básicos e as práticas operacionais. Rio de Janeiro: COPPEAD/UFRJ, 6.

Marchesini, M. M. P., \& Alcântara, R. L. C. (2016). Logistics activities in supply chain business process: A conceptual framework to guide their implementation. The International Journal of Logistics Management, 27(1), 6-30.

Market Inteligence Brazil (DATAMARK). (2015). Mercado Embalagens - 2014. Disponível em: <http://www.datamark.com.br/dados-gerais/> Acesso em: 18 mai, 2017.

Martins, G. A. \& Domingues, O. (2000). Estatística geral e aplicada . Editora Atlas SA.

Ministério do Meio Ambiente (MMA). (2017). Impacto das embalagens no meio ambiente. Disponível em: http://www.mma.gov.br/responsabilidade-socioambiental/producao-econsumo-sustentavel/consumo-consciente-de-embalagem/impacto-das-embalagens-nomeio-ambiente. Acesso em: 16 mai, 2017.

Ministério do Meio Ambiente. (2016). Coleta Seletiva. Disponível em: http://www.mma.gov.br/cidades-sustentaveis/residuos-solidos/catadores-de-materiaisreciclaveis/reciclagem-e-reaproveitamento. Acesso em: 26 set. $2016 \mathrm{~b}$

Ministério do Meio Ambiente. (2016). Lixo: um grande problema do mundo moderno. Disponível em: http://www.mma.gov.br/estruturas/secex_consumo/_arquivos/8\%20$\% 20$ mcs_lixo.pdf. Acesso em 19 out 2016c.

Ministério do Meio Ambiente. (2016). Política Nacional de Resíduos Sólidos. Disponível em: http://www.mma.gov.br/pol\%C3\%ADtica-de-res\%C3\%ADduos-s\%C3\%B3lidos. Acesso em: 21 jul 2016d. 
Montgomery, D. C., Peck, E. A., \& Vining, G. G. (2012). Introduction to linear regression analysis (Vol. 821). John Wiley \& Sons.

Naspolini Júnior, O. \& Guadagnin, M. R. (2014). A função de empresa aparista na cadeia de reciclagem de papel e papelão no sul catarinense.

Oliveira, C. E. de, Cândido, T. L., \& Lima, B. A. (2019). A incidência da inovação em responsabilidade social corporativa nas empresas do setor elétrico. International Journal of Innovation, 7(3), 431-447. doi:10.5585/iji.v7i3.171

Parente, J. (2000). Varejo no Brasil: gestão e estratégia. Editora Atlas.

Parente, J., \& Gelman, J. J. (2009). Varejo e responsabilidade social. Bookman Editora.

Saab, W. G. L., \& Gimenez, L. C. P. (2000). Aspectos atuais do varejo de alimentos no mundo e no Brasil.

Schor, J. (2010). Plenitude: The new economics of true wealth. New York: Penguin Press.

Senhoras, E. M. (2003). O varejo supermercadista sob perspectiva. Revista Eletrônica de administração, 9(3).

Tibben-Lembke, R. S. (1998). The impact of reverse logistics on the total cost of ownership. Journal of Marketing Theory and Practice, 6(4), 51-60.

Tibben-Lembke, R. S., \& Rogers, D. S. (2002). Differences between forward and reverse logistics in a retail environment. Supply Chain Management: An International Journal, 7(5), 271-282.

Vlachos, I. P. (2014). Reverse food logistics during the product life cycle. International Journal of Integrated Supply Management, 9(1-2), 49-83.

Winandy, A. J. C., \& Gallardo, A. L. C. F. (2014). Análise das práticas de gestão ambiental divulgadas pelo varejo supermercadista. Revista Gestão Industrial, 10(4). 